\title{
ICINCO 2010
}

Proceedings of the

7th International Conference on

Informatics in Control, Automation and Robotics

Volume 2

Funchal, Madeira, Portugal

June $15-18,2010$

Co-Sponsored by

INSTICC - Institute for Systems and Technologies of Information, Control and Communication

IFAC - International Federation of Automatic Control

In Cooperation with

AAAI - Association for the Advancement of Artificial Intelligence

WfMC - Workflow Management Coalition

APCA - Associação Portuguesa de Controlo Automático

ACM SIGART - Association for Computing Machinery / Special Interest

Group on Artificial Intelligence 
Copyright (C) 2010 SciTePress - Science and Technology Publications All rights reserved

Edited by Joaquim Filipe, Juan Andrade Cetto and Jean-Louis Ferrier

Printed in Portugal

ISBN: 978-989-8425-01-0

Depósito Legal: 311149/10

http://www.icinco.org

icinco.secretariat@insticc.org 


\section{CONTENTS}

\section{INVITED SPEAKERS}

\section{KEYNOTE SPEAKERS}

BIOINSPIRED ROBOTICS AND VISION WITH HUMANOID ROBOTS

José Santos-Victor

IS-5

HUMAN - Robot Cooperation Techniques in Surgery

Alicia Casals

IS-7

MAKING MICROROBOTS MOVE

Bradley Nelson

IS-13

DYNAMIC MODELING OF ROBOTS USING RECURSIVE NEWTON-EULER TECHNIQUES Wissama Khalil

IS-19

EMOTIVE DRIVER ADVISORY SYSTEM

Oleg Gusikhin

IS-33

FINGERTIP FORCE MEASUREMENT BY IMAGING THE FINGERNAIL

John Hollerbach

IS-35

\section{ROBOTICS AND AUTOMATION}

\section{Full Papers}

POSITION ESTIMATION OF MOBILE ROBOTS CONSIDERING CHARACTERISTIC TERRAIN PROPERTIES

Michael Brunner, Dirk Schulz and Armin B. Cremers

SELECTION OF DIFFERENT PATHS FOR DOUBLY NONHOLONOMIC MOBILE MANIPULATORS

Alicja Mazur and Elżbieta Roszkowska

ON REAL-TIME WHOLE-BODY HUMAN TO HUMANOID MOTION TRANSFER

Francisco-Javier Montecillo-Puente, Manish N. Sreenivasa and Jean-Paul Laumond

FREQUENCY EXTRACTION BASED ON ADAPTIVE FOURIER SERIES - Application to Robotic Yoyo

Tadej Petrič, Andrej Gams and Leon Žlajpah

BILATERAL TELEOPERATION FOR FORCE SENSORLESS 1-DOF ROBOTS

Stefan Lichiardopol, Nathan van de Wouw and Henk Nijmeijer

GRASPING WITH VISION DESCRIPTORS AND MOTOR PRIMITIVES

Oliver Kroemer, Renaud Detry, Justus Piater and Jan Peters

REMOTE CONTROL OF A MOBILE ROBOT SUBJECT TO A COMMUNICATION DELAY A. Alvarez-Aguirre, H. Nijmeijer, T. Oguchi and K. Kojima

PERFORMANCE OF HIGH-LEVEL AND LOW-LEVEL CONTROL FOR COORDINATION OF MOBILE ROBOTS

Sisdarmanto Adinandra, Jurjen Caarls, Dragan Kostić and Hendrik Nijmeijer 
A HIGHLY INTEGRATED LOW PRESSURE FLUID SERVO-VALVE FOR APPLICATIONS IN WEARABLE ROBOTIC SYSTEMS

Michele Folgheraiter, Mathias Jordan, Luis M. Vaca Benitez, Felix Grimminger, Steffen Schmidt, Jan Albiez and Frank Kirchner

COLLECTIVE LEARNING OF CONCEPTS USING A ROBOT TEAM

Ana Cristina Palacios-García, Angélica Muñoz-Meléndez and Eduardo F. Morales

DYNAMIC MODELING AND PNEUMATIC SWITCHING CONTROL OF A SUBMERSIBLE DROGUE

Y. Han, R. A. de Callafon, J. Cortés and J. Jaffe

VISUAL-BASED DETECTION AND TRACKING OF DYNAMIC OBSTACLES FROM A MOBILE ROBOT

Dora Luz Almanza-Ojeda, Michel Devy and Ariane Herbulot

\section{ShORT PAPERS}

AUTONOMOUS MANEUVERS OF A FARM VEHICLE WITH A TRAILED IMPLEMENT IN HEADLAND

Christophe Cariou, Roland Lenain, Michel Berducat and Benoit Thuilot

AUTOMATED 2D MEASURING OF INTERIORS USING A MOBILE PLATFORM

Alexander Fietz, Sebastian M. Jackisch, Benjamin A. Visel and Dieter Fritsch

AUTOMATIC CALIBRATION OF A MOTION CAPTURE SYSTEM BASED ON INERTIAL SENSORS FOR TELE-MANIPULATION

Jörg Hoffmann, Bernd Brüggemann and Björn Krüger

LEGS DETECTION USING A LASER RANGE FINDER FOR HUMAN ROBOT INTERACTION

Flávio Garcia Pereira, Raquel Frizera Vassallo and Evandro Ottoni Teatini Salles

FORMATION CONTROL BETWEEN A HUMAN AND A MOBILE ROBOT BASED ON STEREO VISION

Flávio Garcia Pereira, Marino Frank Cypriano and Raquel Frizera Vassallo

NAVIGATION AND FORMATION CONTROL EMPLOYING COMPLEMENTARY VIRTUAL LEADERS FOR COMPLEX MANEUVERS

Martin Saska, Vojtěch Vonásek and Libor Přeučil

SMA CONTROL FOR BIO-MIMETIC FISH LOCOMOTION

Claudio Rossi, Antonio Barrientos and William Coral Cuellar

EJS+EJSRL: A FREE JAVA TOOL FOR ADVANCED ROBOTICS SIMULATION AND COMPUTER VISION PROCESSING

Carlos A. Jara, Francisco A. Candelas, Jorge Pomares, Pablo Gil and Fernando Torres

FORMATION CONTROL OF MULTI-ROBOTS VIA SLIDING-MODE TECHNIQUE

Razvan Solea, Daniela Cernega, Adrian Filipescu and Adriana Serbencu

KINEMATIC IDENTIFICATION OF PARALLEL MECHANISMS BY A DIVIDE AND CONQUER STRATEGY

Sebastián Durango, David Restrepo, Oscar Ruiz, John Restrepo-Giraldo and Sofiane Achiche

A CASTOR WHEEL CONTROLLER FOR DIFFERENTIAL DRIVE WHEELCHAIRS

Bernd Gersdorf and Shi Hui 
DISTRIBUTED OPTIMIZATION BY WEIGHTED ONTOLOGIES IN MOBILE ROBOT SYSTEMS

Lucia Vacariu, George Fodor, Gheorghe Lazea and Octavian Cret

OFFROAD NAVIGATION USING ADAPTABLE MOTION PATTERNS

Frank Hoeller, Timo Röhling and Dirk Schulz

EVALUATION OF FEEDBACK AND FEEDFORWARD LINEARIZATION STRATEGIES FOR AN ARTICULATED ROBOT

Roland Riepl, Hubert Gattringer and Hartmut Bremer

EXPERIMENTS WITH A CONTINUUM ROBOT STRUCTURE

Dorian Cojocaru, Sorin Dumitru, Florin Manta, Giuseppe Boccolato and Ion Manea

A ROBUST MOSAICING METHOD FOR ROBOTIC ASSISTED MINIMALLY INVASIVE SURGERY

Mingxing Hu, David J. Hawkes, Graeme P. Penney, Daniel Rueckert, Philip J. Edwards, Fernado Bello,

Michael Figl and Roberto Casula

ROBOT SKILL SYNTHESIS THROUGH HUMAN VISUO-MOTOR LEARNING - Humanoid Robot Statically-stable Reaching and In-place Stepping

Jan Babič, Blaž Hajdinjak and Erhan Oztop

DYNAMIC MODELING OF A MOMENT EXCHANGE UNICYCLE ROBOT

S. Langius and R. A. de Callafon

MULTI-SCALE COLLABORATIVE SEARCHING THROUGH SWARMING

Wangyi Liu, Yasser E. Taima, Martin B. Short and Andrea L. Bertozzi

LOCALIZATION IN AN AUTONOMOUS UNDERWATER MULTI-ROBOT SYSTEM DESIGNED FOR COASTAL AREA MONITORING

Zhongliang Hu, Eemeli Aro, Tapani Stipa, Mika Vainio and Aarne Halme

PARTICLE SWARM OPTIMIZATION USED FOR THE MOBILE ROBOT TRAJECTORY TRACKING CONTROL

Adrian Emanoil Serbencu, Adriana Serbencu and Daniela Cristina Cernega

EFFICIENT LOCOMOTION ON NON-WHEELED SNAKE-LIKE ROBOTS

Julián Colorado, Antonio Barrientos, Claudio Rossi, Mario Garzón, María Galán and Jaime del Cerro

DECENTRALISED ACTIVE CONTROLLER

Chiheb Ameur Abid and Belhassen Zouari

A CONSTRAINED FINITE TIME OPTIMAL CONTROLLER FOR THE DIVING AND STEERING PROBLEM OF AN AUTONOMOUS UNDERWATER VEHICLE

George Nikolakopoulos, Nikolaos J. Roussos and Kostas Alexis

A NEW PREDICTOR/CORRECTOR PAIR TO ESTIMATE THE VISUAL FEATURES DEPTH DURING A VISION-BASED NAVIGATION TASK IN AN UNKNOWN ENVIRONMENT - A Solution for Improving the Visual Features Reconstruction During an Occlusion

A. Durand Petiteville, M. Courdesses and V. Cadenat

NORMAL FLAT FORMS FOR A CLASS OF 0-FLAT AFFINE DYNAMICAL SYSTEMS AND ITS APPLICATION TO NONHOLONOMIC SYSTEMS

S. Bououden, D. Boutat and F. Abdessemed 
BEARING-ONLY SAM USING A MINIMAL INVERSE DEPTH PARAMETRIZATION Application to Omnidirectional SLAM

Cyril Joly and Patrick Rives

A FLEXIBLE ROBOTICS AND AUTOMATION SYSTEM - Parallel Visual Processing, Realtime Actuator Control and Task Automation for Limp Object Handling

Thomas Müller, Binh An Tran and Alois Knoll

BIOMIMETIC CONTROL ALGORITHM FOR THE BALANCE AND LOCOMOTION OF WALKING SYSTEMS

Nicu George Bîzdoacă, Anca Petrișor, Hani Hamdan and Khalid Al Mutib

ROBUST 6D POSE DETERMINATION IN COMPLEX ENVIRONMENTS FOR ONE HUNDRED CLASSES

Thilo Grundmann, Robert Eidenberger, Martin Schneider and Michael Fiegert

MINDLAB, A WEB-ACCESSIBLE LABORATORY FOR ADAPTIVE E-EDUCATIONAL ROBOT TELEOPERATION

P. Di Giamberardino, M. Spanò Cuomo and M. Temperini

INTEGRATING CONTEXT INTO INTENT RECOGNITION SYSTEMS

Richard Kelley, Christopher King, Amol Ambardekar, Monica Nicolescu, Mircea Nicolescu and

Alireza Tavakkoli

HAND PROSTHESIS CONTROL - Software Tool for EMG Signal Analysis

Tomasz Suchodolski and Andrzej Wolczowski

REGISTRATION OF INDOOR 3D RANGE IMAGES USING VIRTUAL 2D SCANS

Marco Langerwisch and Bernardo Wagner

\section{Posters}

OBSTACLES AVOIDANCE IN THE FRAME WORK OF PYTHAGOREAN HODOGRAPH BASED PATH PLANNING.

M. A. Shah, A. Tsourdos, P. M. G. Silson, D. James and N. Aouf

MOBILE ROBOT OBSTACLE DETECTION USING AN OVERLAPPED ULTRASONIC SENSOR RING

Sungbok Kim, Jaehee Jang and Hyun Bin Kim

SALT AND PEPPER NOISE DETECTION BASED ON NON-LOCAL MEANS

Carlos Junez-Ferreira, Fernando Velasco-Avalos and Nelio Pastor-Gomez.

PLANNING STACKING OPERATIONS WITH AN UNKNOWN NUMBER OF OBJECTS

Lluis Trilla and Guillem Alenyà

MOTION GENERATION FOR A HUMANOID ROBOT WITH INLINE-SKATE

Nir Ziv, Yong Kwun Lee and Gaetano Ciaravella

TOWARDS HUMAN INSPIRED SEMANTIC SLAM

Dominik Maximilián Ramík, Christophe Sabourin and Kurosh Madani

HOMOTHETIC APPROXIMATIONS FOR STOCHASTIC PN

Dimitri Lefebvre

FDI WITH NEURAL AND NEUROFUZZY APPROACHES - Application to Damadics

Y. Kourd, N. Guersi and D. Lefebvre 
CONSENSUS PROBLEM OF MULTI-AGENT SYSTEMS WITH MARKOVIAN COMMUNICATION FAILURE

Yuebing Hu, James Lam and Jinling Liang

MANIPULATOR-DEPLOYED SYSTEMS FOR SURFACE DECONTAMINATION IN NUCLEAR FACILITIES

Jan Bremmer, Sascha Gentes and Nadine Gabor

DESIGN AND EXPERIMENTAL VERIFICATION OF POWER-ASSISTED SMART DOOR SYSTEM FOR PASSENGER VEHICLE

Kum-Gil Sung, Min-kyu Park and Byoungsoo Lee

IMPACT OF DIFFERENT BIT RATES ON PERFORMANCE CHARACTERISTICS OF INDUSTRIAL WLAN SOLUTIONS

André Schimschar and Lutz Rauchhaupt

SIMULTANEOUS LEARNING OF PERCEPTIONS AND ACTIONS IN AUTONOMOUS ROBOTS

Pablo Quintía, Roberto Iglesias, Miguel Rodríguez and Carlos V. Regueiro

GEOMETRIC FORMATIONS FOR A TEAM OF MOBILE ROBOTS - Odometric-based Maintenance Method for Heterogeneous Teams of Robots

Patricio Nebot and Enric Cervera

PRIORITY SELECTION FOR MULTI-ROBOTS

S. H. Ji, S. M. Lee and W. H. Shon

DEVELOPMENT OF LIGHTWEIGHT DUAL ARM ROBOT BY USING HOLLOW SHAFT SERVO ASSEMBLY

Min-kyu Park, Seok-jo Go and Young-jin Lee

STATIC BALANCE FOR RESCUE ROBOT NAVIGATION - Translation Motion Discretization Issue within Random Step Environment

Evgeni Magid and Takashi Tsubouchi

VISUAL MAP BUILDING AND LOCALIZATION WITH AN APPEARANCE-BASED APPROACH - Comparisons of Techniques to Extract Information of Panoramic Images

Francisco Amorós, Luis Payá, Óscar Reinoso, Lorenzo Fernández and Jose Ma Marín

SELF DEPLOYED ROBOTIC NETWORK FOR LONG RANGE SEMIAUTOMATIC OPERATION - Robotics Network for Distance Data Connection, Areal Signal Connection Coverage or Areal Data Acquisition

Tomas Solarski, David Vala and Jiri Koziorek

ROBOT SOCCER STRATEGY - BIOMIMETIC APPROACH

Nicu George Bîzdoacă, Daniela Coman, Hani Hamdan and Khalid Al Mutib

TOWARDS OBJECT-ORIENTED SOFTWARE DEVELOPMENT FOR INDUSTRIAL ROBOTS - Facilitating the Use of Industrial Robots by Modern Software Engineering

Alwin Hoffmann, Andreas Angerer, Andreas Schierl, Michael Vistein and Wolfgang Reif

DYNAMICAL INVARIANTS FOR CPG CONTROL IN AUTONOMOUS ROBOTS

Fernando Herrero-Carrón, Francisco de Borja Rodríguez and Pablo Varona

LASER BASED TELEROBOTIC CONTROL FOR ASSISTING PERSONS WITH DISABILITIES PERFORM ACTIVITIES OF DAILY LIVING

Karan Khokar, Redwan Alqasemi and Rajiv Dubey 


\title{
EJS+EJSRL: A FREE JAVA TOOL FOR ADVANCED ROBOTICS SIMULATION AND COMPUTER VISION PROCESSING
}

\author{
Carlos A. Jara, Francisco A. Candelas, Jorge Pomares, Pablo Gil and Fernando Torres \\ Physics, Systems Engineering and Signal Theory Department, University of Alicante, Spain \\ \{carlos.jara, francisco.candelas, jpomares, pablo.gil,fernando.torres\}@ua.es
}

\begin{abstract}
Keywords: Modelling, Robotics simulation, Virtual reality.
Abstract: This paper presents a free Java software platform which enables users to easily create advanced robotic applications together with image processing. This novel tool is composed of two layers: 1) Easy Java Simulations (EJS), an open-source tool which provides support for creating applications with a full 2D/3D interactive graphical interface, and 2) EjsRL, a high-level Java library specifically designed for EJS which provides a complete functional framework for modeling of arbitrary serial-link manipulators and computer vision algorithms. The combination of both components sets up a software architecture which contains a high number of functionalities in the same platform to develop complex simulations in robotics and computer vision fields.
\end{abstract}

\section{INTRODUCTION}

Robotics and Computer Vision (R\&CV) systems have highly complex behaviours. For this reason, throughout the last two decades there has been a strong development of simulation tools devoted to R\&CV systems. Some of these tools have been designed for professional applications, while others for educational and research purposes. In the field of industrial Robotics, several graphical software environments as for example Easy-ROB3D (EasyROB3D, 2004), have been created in the form of stand-alone business packages for well defined problems. These are powerful tools, but some of them lack of resources in some aspects for higher education. Otherwise, numerous open-source tools such as GraspIt (Pelossoft et. al, 2004), RoboMosp (Jaramillo et al., 2006) and Microsoft Robotics Studio (Jackson, 2007), overcome these deficiencies. Other open-source tools are in the form of toolboxes such as SimMechanics (SMC) (Babuska, 2005), RobotiCad (RBC) (Falconi and Melchiorri, 2008) and Robotics Toolbox for Matlab (Corke, 1996). With regard to Computer Vision tools, several libraries have been developed for education and research, such as the Open Computer Vision Library (OpenCV, 2001) and VXL (VXL, 2001), developed in C++ language, and Java Advanced Imaging (JAI, 2004), written in Java.

However, the majority of the above commented tools are independent software platforms which have been developed in a separated way. This feature represents a drawback when time comes to develop complex models which combine R\&CV systems. Perhaps, only Robotics/Vision Matlab toolboxes provide a set of functions suitable for synthesis and simulation which can be programmed under the same environment. Nevertheless, both toolboxes do not provide a user-friendly graphical interface support for both creating a personalized application and building 3D virtual environments. Thus, educators and researches have to spend time and effort searching the suitable libraries and they must have programming skills to develop the application.

The approach presented in this paper is a new tool called EJS+EjsRL, which provides a complete functional framework for modeling and simulation of R\&CV systems, all embedded in the same toolbox. In addition, this software platform gives full 2D and 3D graphical support both for creating user interfaces and complex robotic environments with computer vision algorithms in an easy and simplified way. The main novel feature of this approach is that its software architecture contains a higher number of functionalities in the same platform than the existing software applications for that purpose (see table 1). Most of these functionalities are included as highlevel tools, with the advantage of allowing users to easily create $\mathrm{R} \& \mathrm{CV}$ applications with a minimum of programming. The tool presented contains several 
features for Robotics such as kinematics, programming, dynamics, world modeling, importation of 3D model files, etc. and a higher number of Computer Vision algorithms than the JAI.

Table 1: Feature comparison with other toolboxes.

\begin{tabular}{|l|l|l|l|l|}
\hline Feature & SMC & RBC & $\begin{array}{l}\text { Matlab } \\
\text { toolbox }\end{array}$ & $\begin{array}{l}\text { EJS+ } \\
\text { EjsRL }\end{array}$ \\
\hline Kinematics & $\bullet$ & $\bullet$ & $\bullet$ & $\bullet$ \\
\hline Dynamics & $\bullet$ & $\bullet$ & $\bullet$ & $\bullet$ \\
\hline Programming & & $\bullet$ & $\bullet$ & $\bullet$ \\
\hline $\begin{array}{l}\text { Importation } \\
\text { VRML/OBJ }\end{array}$ & & & $\bullet$ & $\bullet$ \\
\hline World Modeling & & & & $\bullet$ \\
\hline $\begin{array}{l}\text { Computer } \\
\text { Vision }\end{array}$ & & & $\bullet$ & $\bullet$ \\
\hline Interface design & & & & $\bullet$ \\
\hline $\begin{array}{l}\text { Software } \\
\text { connection }\end{array}$ & & & $\bullet$ & $\bullet$ \\
\hline
\end{tabular}

Another meaningful problem is the platform dependency. Some $\mathrm{C}++$ tools are not portable for all the operating systems. EJS+EjsRL is based on Java, a well-known programming language which is platform independent.

The remainder of this paper is organized as follows: section 2 describes the overall software architecture of the platform. Section 3 shows a complete application design. Section 4 shows other advanced features of the system. Section 5 shows the simulation capabilities of EJS+EjsRL by means of several test cases. Finally, some conclusions are discussed in section 6 .

\section{SYSTEM DESCRIPTION}

\subsection{Components}

There are two main blocks that represent the functional core of this software platform: an objectoriented Java library (EjsRL) which allows users to model both arbitrary serial-link robots and computer vision algorithms, and Easy Java Simulations (EJS), powerful software for developing simulations. The combination of both tools (EJS+EjsRL) permits to easily and quickly create R\&CV simulations.

EJS is a freeware, open-source tool developed in Java, specifically created for the creation of interactive dynamic simulations with higher graphical support (Esquembre, 2004). EJS has been designed for people who do not need complex programming skills. In order to develop a simulation, the user only provides the most relevant core of the algorithm and EJS automatically generates all the Java code needed to create a complete interactive application. There are a lot of applications which have been developed with EJS for research and teaching activities (Jara et al., 2008; Jara et al., 2009).

EjsRL is a Java library specifically designed for EJS which provides a complete functional framework that enables it to model and design advanced R\&CV applications. All the components belonging to this software layer have been structured and organized in an object-oriented form. Figure 1 shows a simplified class diagram of EjsRL, specifying the most important packages and classes. For a complete description of all the classes, readers can visit the web page: http://www.aurova.ua.es/rcv.

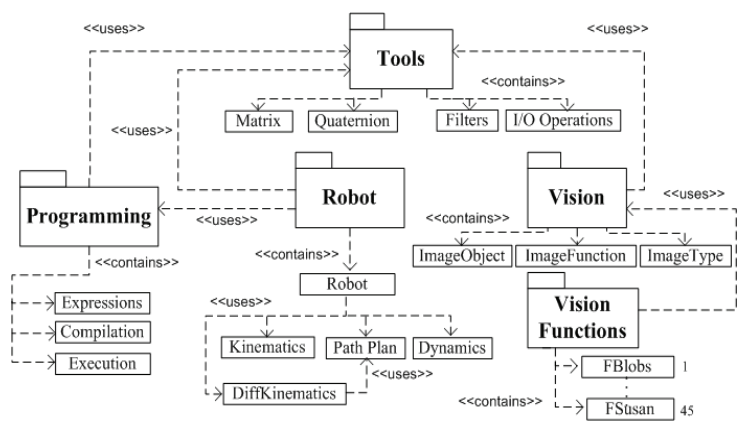

Figure 1: Package and class diagram of EjsRL.

\subsection{Software Architecture}

The software design is based on a hierarchical coordination between EJS and EjsRL. Each of them is divided into systems which must interchange data in order to develop R\&CV simulations (figure 2).

A specific simulation within the EJS' environment must include the definition of the model and the definition of the view or graphical interface (figure 2). In order to describe the model, users must write the differential equations that establish how these variables change in time. For this last step, EJS offers two options. The first is a built-in editor of Ordinary Differential Equations (ODEs) in which users write the system equations in a similar way to how they would write on a blackboard. Users can choose different standard algorithms to numerically solve them (Euler, RungeKutta, etc.). The second facility is a connection with Matlab/Simulink that lets users to model systems with the help of these tools (Sanchez et al., 2005) (see section 5). In relation to the view, EJS provides a set of standard Java Swing, Java 2D and Java 3D components to build the interface in a simple dragand-drop way. In addition, VRML and OBJ extern graphic files can be imported to the view. These 
graphical components have certain properties that the user can connect with the model variables and set a link between the model and the view. Therefore, the simulation turns into an interactive application where users can change the model variables and observe the simulation behaviour in the view.

There are three important modules which define the most high-level API of EjsRL (figure 2): Robotics, Matrix Computation and Computer Vision. This library works as an external interface to give to model variables of EJS the corresponding value in order to create $\mathrm{R} \& \mathrm{CV}$ applications.

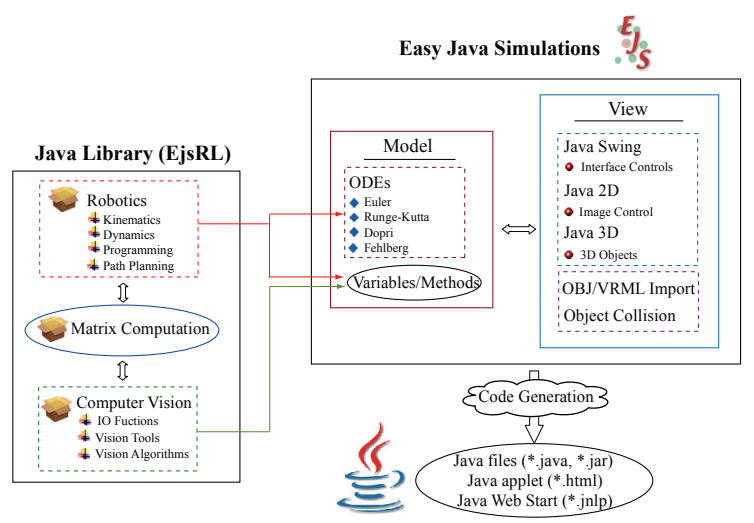

Figure 2: Software architecture of EJS+EjsRL.

\section{DESIGN OF A ROBOTICS APPLICATION}

\subsection{Creating the Robot Arm and its Workspace}

The first step in order to create a robotic simulation is to execute EJS and to insert the library EjsRL as external resource (figure 3). In this way, all the methods and classes of EjsRL can be used within EJS' environment. Secondly, it is necessary to create a specific robot in the model part. This action implicates to define the variables and to program a robot object specifying a minimum code.

For creating an arbitrary robot arm object, users only have to know its Denavit-Hartenberg parameters, its physical features and the type of joints. With these data, a Java object variable defined in the EJS' environment has to be initialized using the robot's constructor of the Robotics module of EjsRL. Figure 4 shows the Java code which must be inserted in the model of EJS'

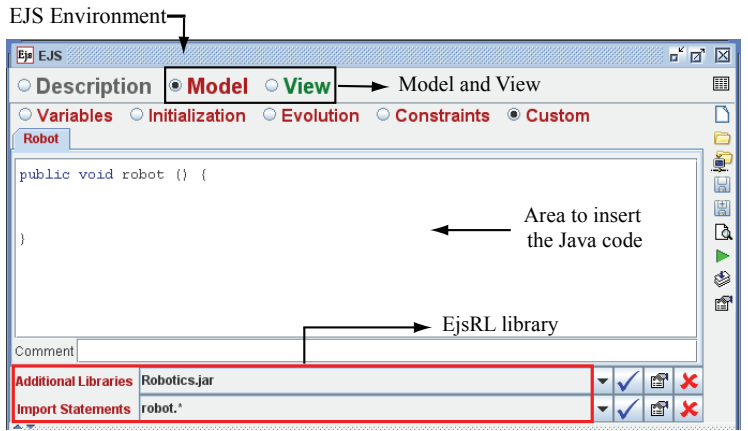

Figure 3: Overview of the EJS' environment

environment and the necessary variables to program a robot of 6 rotational DOF.

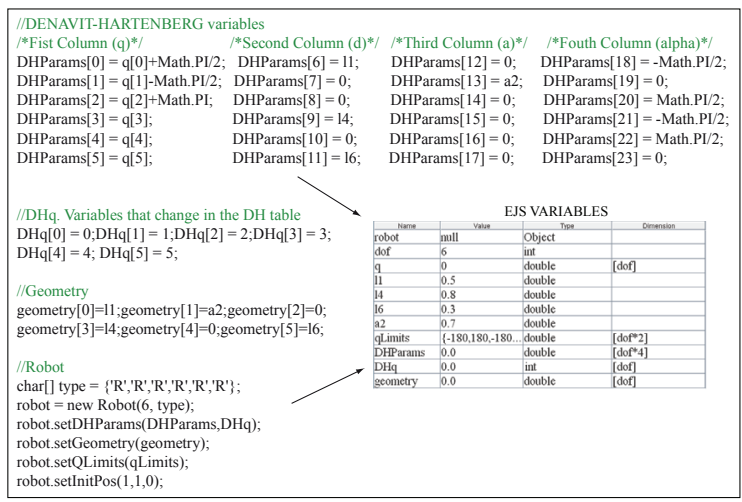

Figure 4: Java code for modeling a 6 rotational DOF robot.

After programming the robot object, the next step is to develop the interface or view for the final user. As stated, EJS provides a set of components to build the interface in a simple drag-and-drop way. In the case of a robotic simulation, the interface can be composed by the $3 \mathrm{D}$ solid links of the robot and its workspace, and other standard components to control the application (panels, buttons, sliders, plots, etc.). Figure 5 shows the construction of the interface for the example proposed. The component drawingPanel $3 D$ is the $3 \mathrm{D}$ environment where the robot and its workspace will be displayed. Here, it is defined each one of the 3D links of the robot by means of the VRML component, which allows to import models from existent VRML files. As mentioned, all the interface components of EJS have certain properties which are used for the simulation. Figure 5 shows the properties of the VRML component (Position and Size, Visibility and Interaction and Graphical Aspect). The position and transform fields will be used to move the robot since they will be connected with the model variables which define the robot. Figure 5 also shows a dialog 
(Move Joints) where some sliders controls $(q 1 \ldots q 0)$ have been added from the view components. These sliders are connected with the $q$ variable of the robot model (see figure 4).

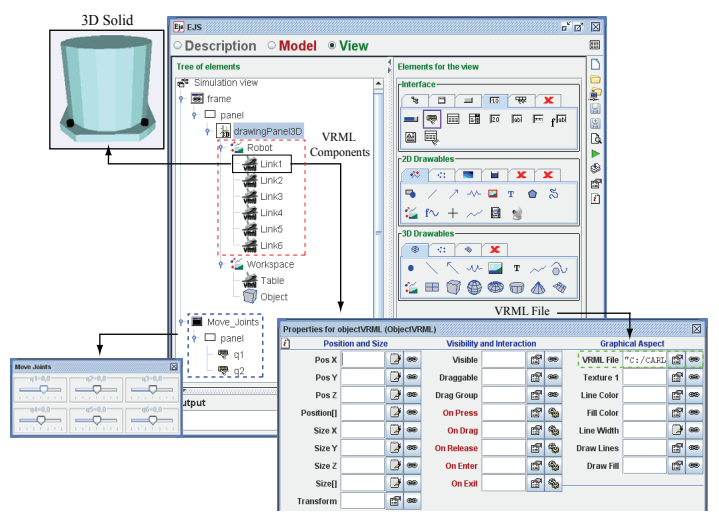

Figure 5: Interface construction of a Robotics application.

\subsection{Kinematics and Path Planning Simulation}

The implementation of the forward kinematics can be easily programmed and simulated with EJS+EjsRL. Figure 6 shows the Java code to resolve the forward kinematics of the robot proposed. The joint values are got from the interface Move Joints for updating the DHParams array of the model. Afterwards, the homogeneous transformations of each link are computed using the method FKinematics of the Robotics module of EjsRL. Finally, these matrix objects $(A 01 \ldots A 06)$ are inserted in the property Transform (figure 5) of the VRML components in order to move them according this kinematics algorithm.

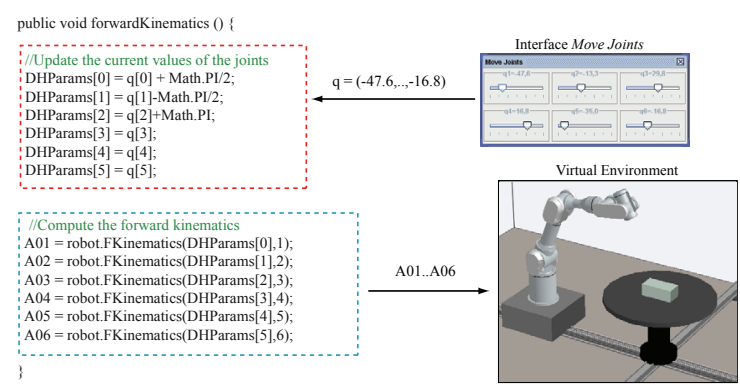

Figure 6: Java code for the forward kinematics of a 6 rotational DOF robot.

EjsRL contains some methods to solve the inverse kinematics problem. Figure 7 shows an example for solving this based on the Jacobian operator. The method IKinematics receives the position and orientation of the end effector (Matrix
$T$ ) and the current joint values of the robot (array q_current) as input parameters. Finally, the robot is moved to the suitable position using the forward kinematics method described before.

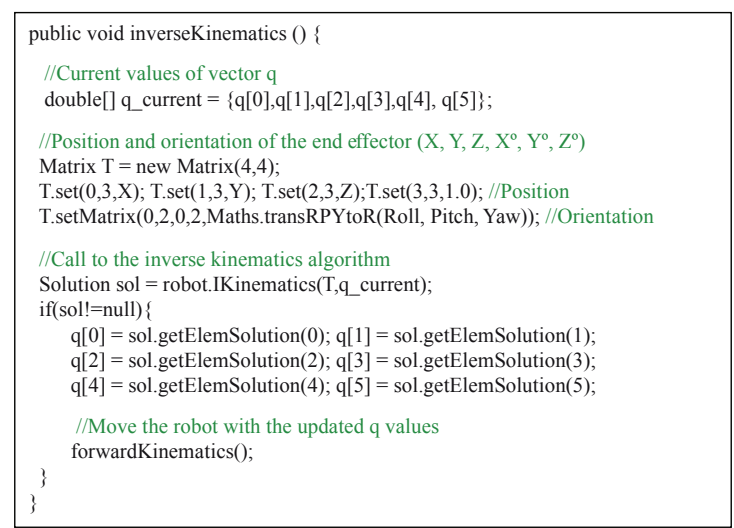

Figure 7: Java code for the inverse kinematics problem.

With regard to trajectory planning, EJS+EjsRL allows users to easily perform the simulation of many path planning algorithms for n-axis robot arms. The ODEs editor implemented in EJS is employed to generate the position, velocity and acceleration values. The Robotics classes of EjsRL contain a path planning module which computes the acceleration parameters of several trajectories from their imposed constrains. Thus, two steps are only necessary to create a planning algorithm for a n-axis robot manipulator:

- To write the equations of the basic motion of a multi-body system. Figure 8 shows these equations in the ODEs editor of EJS. These equations compute the sequence values of the position $(q)$ and velocity (VPlan) of all the robot joints from the acceleration of the trajectory (APlan);

- To compute the acceleration of the path planning algorithm proposed using one of the functions provided by the Robotics package. The trajectory planning module returns the acceleration parameters of several kinds of trajectories which can be used in the motion equations;

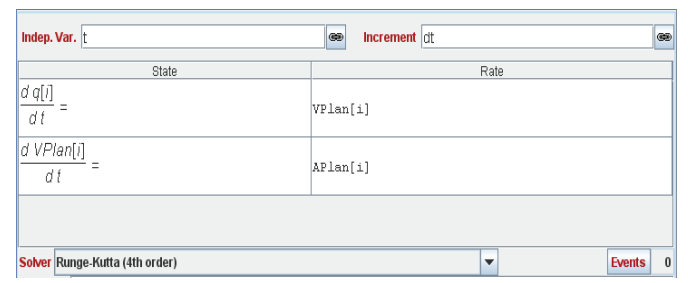

Figure 8: ODEs of basic robot motion. 
There are a lot of methods implemented in the Robotics module: splines, cubic interpolators, synchronous, asynchronous and linear trajectories, and the 4-3-4 polynomial path planning algorithm. Figure 9 shows the Java code to program this last interpolator in order to determinate the acceleration array for the differential equations.

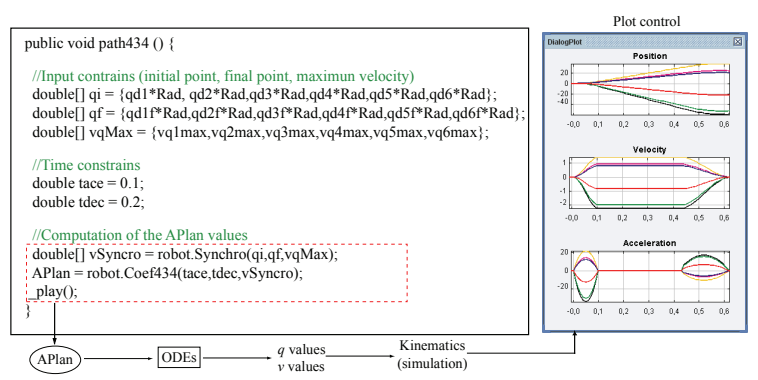

Figure 9: Simulation of a 4-3-4 polynomial trajectory.

The generated joint values are automatically given to the kinematics model to simulate the robot movement (method play). In addition, EJS plot controls can be used to visualize the trajectory variables (figure 9).

\subsection{Dynamics Features}

The Robotics module of EjsRL implements numerical methods to solve the forward and inverse dynamics problems (Newton-Euler and WalkerOrin, respectively). Figure 10 shows an example which obtains the inverse dynamics with an external force. Mass, inertias and friction properties must be known in order to solve this algorithm. The array variables VPlan and APlan belong to the velocity and acceleration of the path planning previously computed.

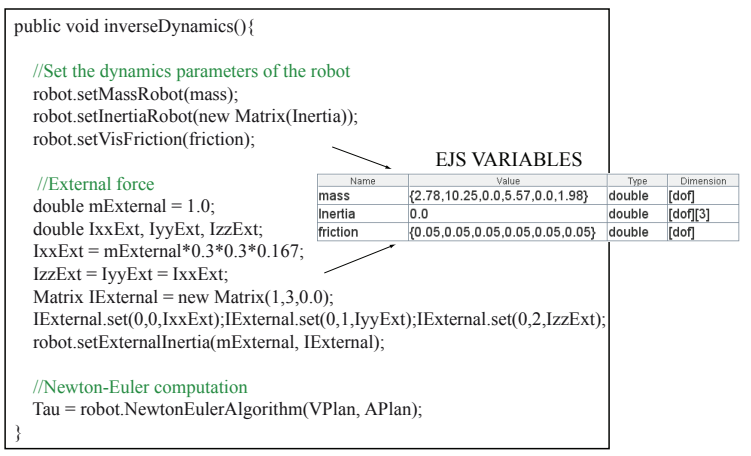

Figure 10: Programming the inverse dynamics with an external force.

\subsection{Using Computer Vision Features}

The Computer Vision classes of EjsRL provide a complete library for the development of image processing algorithms within EJS' environment. There are approximately fifty different functions implemented in this module, ranging from basic operations (format conversion, image adjustment, histogram, etc.) to image feature extraction (point and edge features). As example, authors implement a computer vision algorithm in the virtual robotic environment previously created. The aim is to perform an Eye-In-Hand (EIH) vision based control using four corner features in the control loop.

First of all, it is necessary to obtain a view projection from the end effector of the robot. For that end, EJS has an option which allows users to create a virtual camera in the $3 \mathrm{D}$ robotic environment. Figure 12 shows the appearance of the interface developed where the window "Virtual Camera" shows the projection of the EIH virtual camera. Secondly, this projection must be processed in order to extract the corner features of the object. Figure 11 shows the Java code which computes corner detection in the virtual camera's image (this code can also be used for real images). Initially, the image of the virtual camera control is obtained (variable vcamera) and the image objects are created. Afterwards, the processing algorithm is defined by means of the ImageFunction interface. Finally, the image is processed (processImag method), the point features are detected using one of the implemented algorithms, for example the SUSAN method (Smith and Brady, 1997), and these are returned as an array variable. These point features can be seen in the window "Virtual Image" of the figure 12 .

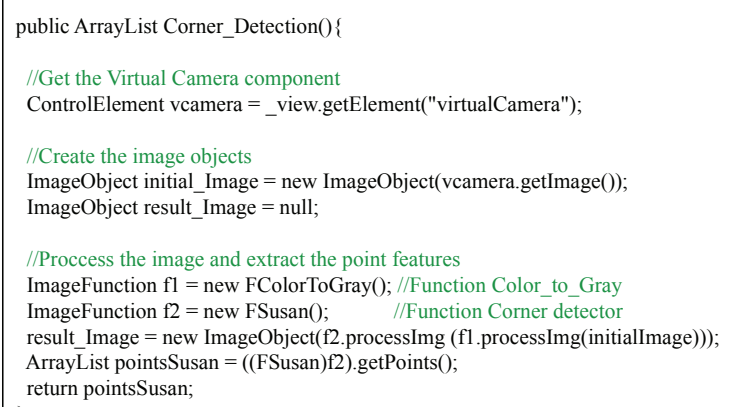

Figure 11: Java code for detecting corner features in the virtual image.

The control action and the interaction matrix used in this control algorithm are based on a 


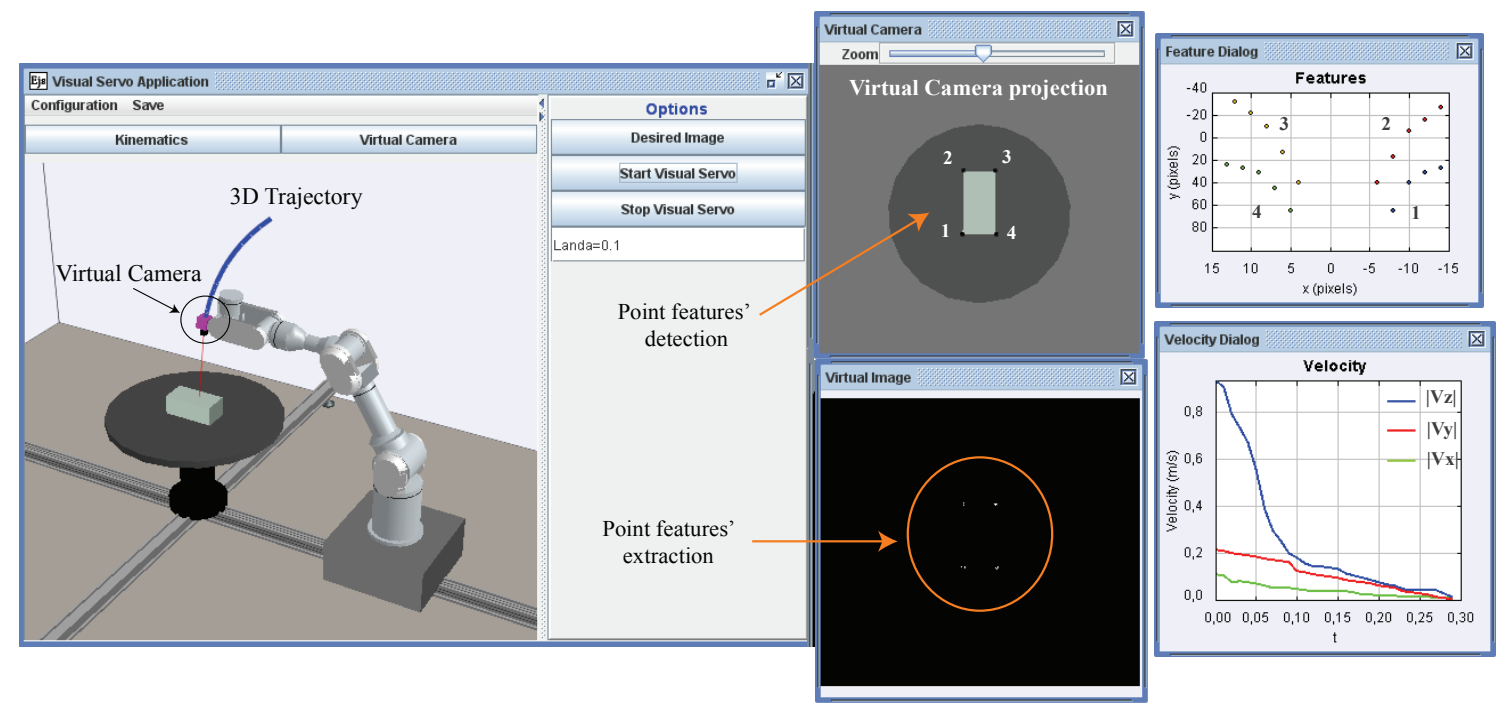

Figure 12: Simulation of a visual-servoing task using point features.

classical 2D visual servoing task, according to the following expressions:

$$
\begin{aligned}
& \mathbf{v}_{\mathrm{c}}=-\lambda \hat{\mathbf{L}}_{\mathrm{s}}^{+}\left(\mathbf{s}-\mathbf{s}^{*}\right) \\
& \hat{\mathbf{L}}_{\mathrm{si}}=\left[\begin{array}{cccccc}
-1 / \mathrm{Z}_{\mathrm{i}} & 0 & \mathrm{x}_{\mathrm{i}} / \mathrm{Z}_{\mathrm{i}} & \mathrm{x}_{\mathrm{i}} \mathrm{y}_{\mathrm{i}} & -\left(1+\mathrm{x}_{\mathrm{i}}{ }^{2}\right) & \mathrm{y}_{\mathrm{i}} \\
0 & -1 / \mathrm{Z}_{\mathrm{i}} & \mathrm{y}_{\mathrm{i}} / \mathrm{Z}_{\mathrm{i}} & 1+\mathrm{y}_{\mathrm{i}}{ }^{2} & -\mathrm{x}_{\mathrm{i}} \mathrm{y}_{\mathrm{i}} & -\mathrm{x}_{\mathrm{i}}
\end{array}\right] \\
& \hat{\mathbf{L}}_{\mathrm{s}}^{\mathrm{T}}=\left[\begin{array}{llll}
\hat{\mathbf{L}}_{\mathrm{s} 1} & \hat{\mathbf{L}}_{\mathrm{s} 2} & \hat{\mathbf{L}}_{\mathrm{s} 3} & \hat{\mathbf{L}}_{\mathrm{s} 4}
\end{array}\right]
\end{aligned}
$$

where $s$ are the current visual features, $s^{*}$ are the desired visual features, and $\lambda$ is the proportional controller; $(x i, y i)$ are the point coordinates of each feature; and $Z i$ is the current distance from the camera to the each feature. The evolution of both velocity module and point features are showed in figure 12 , which validate the correct convergence of the visual servo task.

\section{ADVANCED FEATURES}

EJS has a connection with Matlab/Simulink which lets users specify and solve their models with the help of these tools (Sanchez et al., 2005). Next, authors show a decoupled control of a 3 rotational DOF robot where the electrical model is computed by a Simulink diagram and the 3D graphical interface is developed using EJS+EjsRL. Figure 13 shows the appearance of the application.

In the upper part of this figure, it can be seen the simulation of the robot with its respective plot controls, which show the input and the output values. Simulink diagram is set up by the PID control of each DOF, the power amplifier stage and the engine blocks with the model of a DC motor. The torque values are transferred to the forward dynamics method of EjsRL to compute the acceleration for the path planning algorithm. Feedback variables $q$ and $v$ are values obtained directly from the path planning and connected with the Simulink blocks.

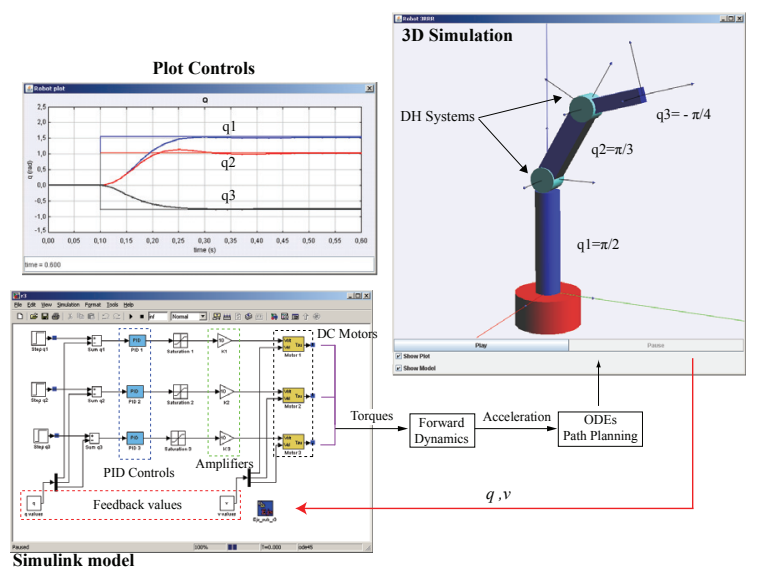

Figure 13: Position control of a robot using EJS+EjsRL and Simulink.

\section{EXPERIMENTAL EXAMPLES}

\subsection{A Virtual and Remote Laboratory}

Authors have developed with EJS+EjsRL a virtual and remote laboratory for training in Robotics. This 
system, called RobUALab.ejs (Jara et al., 2008), allows users to simulate path planning algorithms in a virtual robotic environment, as well as execute remote commands in a real robotic plant.

Programming classes of EjsRL (figure 1, package "Programming") enable users to develop Java routines in a robotic simulation. Figure 14 shows a programming experiment which consists of doing pick-and-place operations of virtual objects located in the conveyor belt using synchronous trajectories (parameter "Syn" in the method moveJ).

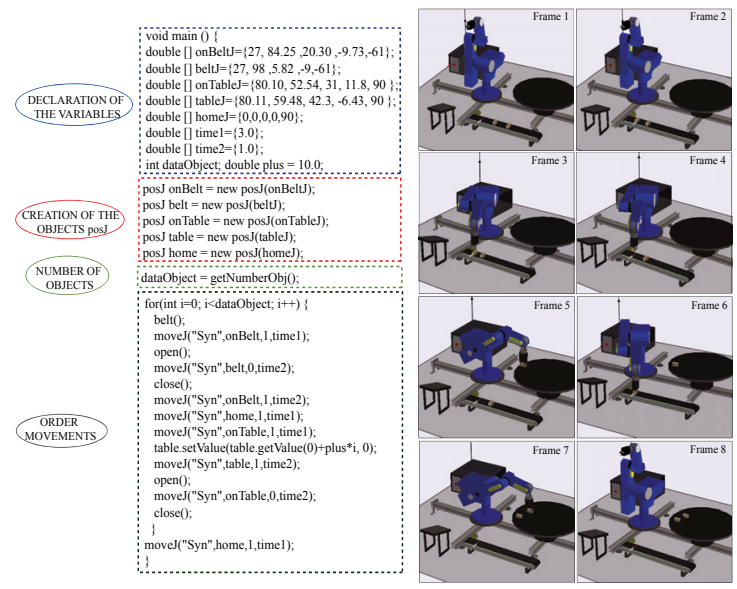

Figure 14: States of the virtual robot during the execution of the programming experiment.

\subsection{A Multi-robot System}

EjsRL allows users the instantiation of different robot objects. Thus, it is possible to developed multi-robot simulations in an easy way. As example, a multi-robotic system composed by a PA-10 robot of 7 rotational DOF and a 3 rotational DOF robot (RRR) is presented here. This last serial robot is attached to a link of the upper part of the PA-10 (figure 15). In addition, the robot RRR has a virtual camera at the end as an EIH configuration. Figure 15 shows the interface of the application developed: on the left, the 3D virtual environment of the workspace; on the right, the virtual projection of the EIH camera located at RRR.

\section{CONCLUSIONS}

In this paper, a free Java-based software platform for the creation of advanced R\&CV applications has been presented. EJS+EjsRL is a suitable tool to develop research and educational simulations in R\&CV systems. The paper has showed several

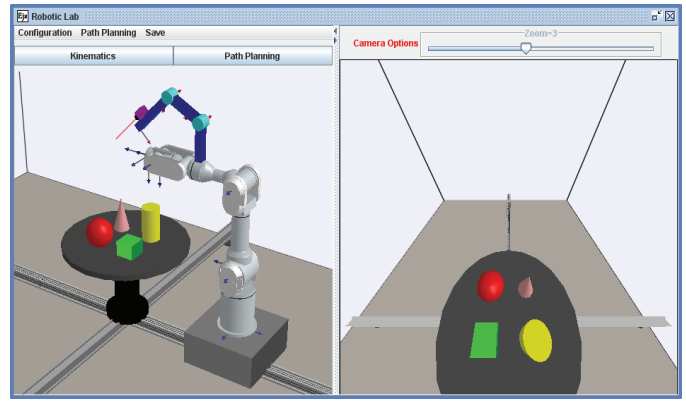

Figure 15: Appearance of the interface of a multi-robot simulation.

high-level applications which illustrate a part of the possibilities of EJS+EjsRL. More information can be obtained from http://www.aurova.ua.es/rcv, where readers can also execute a lot of test examples.

\section{ACKNOWLEDGEMENTS}

The work presented in this paper is supported by the Spanish Ministry of Education and Science (MEC) through the research project DPI2008-02647.

\section{REFERENCES}

Babuska, R. (2005). Design Environment for Robotic Manipulators. In Proceedings of the 16th IFAC World Congress, vol. 16, Prague.

Corke, P. (1996). A Robotics Toolbox for MATLAB. IEEE Robotics and Automation Magazine, 3(1): 2432.

Easy-ROB Software (2004). http://www.easy-rob.com/.

Esquembre, F. (2004). Easy Java Simulations: A software tool to create scientific simulations in Java. Computer Physics Communications, 156(2): 199-204.

Falconi, R. and Melchiorri, C. (2008). Roboticad: An Educational Tool for Robotics. In Proceedings of the 17th IFAC World Congress, vol. 17, Seoul.

Gourdeau, R. (1997). Object-oriented programming for robotic manipulator simulation. IEEE Robotics \& Automation Magazine, 4(1): 21-29.

Jackson, J. (2007). Microsoft Robotics studio: A technical introduction. IEEE Robotics \& Automation Magazine, 14(1): 82-87.

Jara, C., Candelas, F. and Torres, F. (2008). An advanced interactive interface for Robotics e-learning. International Journal of On-line Engineering, 4(1): 17-25.

Jara, C., Candelas F., Torres, F., Esquembre, F., Dormido, S. and Reinoso, O. (2009). Real-time collaboration of virtual laboratories through the Internet. Computers \& Education, 52(1): 126-140. 
ICINCO 2010 - 7th International Conference on Informatics in Control, Automation and Robotics

Jaramillo, A., Matta, A., Correa, F. and Perea, W. (2006). ROBOMOSP. IEEE Robotics \& Automation Magazine, 13(1): 62-73.

Java Advanced Imaging library (JAI) (2004). http://java.sun.com/products/javamedia/jai.

Open Source Computer Vision Library (2001). http://www.intel.com/research/mrl/research/opencv.

Pelossof, R., Miller, A., Allen, P and Jebara, T. (2004). An SVM learning approach to robotic grasping. In Proceedings of the IEEE International Conference on Robotics and Automation, vol. 21, Taiwan.

Sanchez, J., Esquembre, F., Martín, C., Dormido, S., Dormido-Canto, S., Canto, R., Pastor, R. and Urquia, A. (2005). Easy Java Simulations: an open-source tool to develop interactive virtual laboratories using MATLAB/Simulink. International Journal of Engineering Education, 21(5): 789-813.

Smith, S. and Brady, J. (1997). SUSAN: a new approach to low level image processing. International Journal of Computer Vision, 23(1): 45-78.

VXL libraries (2001). http://vxl.sourceforge.net/. 


\section{AUTHOR INDEX}

Abdessemed, F. ..................... 275

Abid, C. .........................252

Achiche, S. ...................... 167

Adinandra, S. . . ...................6 63

Albiez, J. ....................... 72

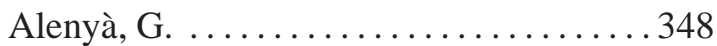

Alexis, K. ....................... 260

Almanza-Ojeda, D. . ................. 98

Alqasemi, R. .................... 446

Alvarez-Aguirre, A. ................55

Ambardekar, A. .................... 315

Amorós, F. .......................423

Angerer, A. ....................... 437

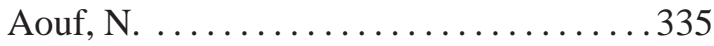

Aro, E. ......................... 232

Babič, J. .......................212

Barrientos, A. ............... 147, 246

Bello, F. ....................... 206

Benitez, L. ....................... 72

Berducat, M. ...................... 109

Bertozzi, A. . . . . . . . . . .........222

Bîzdoacă, N. . . . . ............. 295, 433

Boccolato, G. .................... 198

Bououden, S. . . ................. 275

Boutat, D. ..................... 275

Bremer, H. . . . . . . . . . . . . . . . . . . 192

Bremmer, J. . . . . . . . . . . . . . . . . . 377

Brüggemann, B. . . . . . . . . . . . . . . 121

Brunner, M. ...................... 5

Caarls, J. ........................6 63

Cadenat, V. . ......................... 268

Callafon, R. .................. 89, 216

Candelas, F. ......................... 153

Cariou, C. .......................... 109

Casula, R. ........................ 206

Cernega, D. .................. 161, 240

Cerro, J. ........................246

Cervera, E. ....................... 399

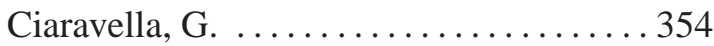

Cojocaru, D. ...................... 198

Colorado, J. ...................... 246

Coman, D. ...................... 433

Cortés, J. ....................... 89

Courdesses, M. ....................268

Cremers, A. ..................... 5
Cret, O. ........................ 180

Cuellar, W. ......................... 147

Cuomo, M. ........................ 309

Cypriano, M. ......................135

Detry, R. .......................47

Devy, M. ...................... 98

Dubey, R. ........................446

Dumitru, S. . . . . . . . . . . . . . . . 198

Durango, S. ...................... 167

Edwards, P. ..................... 206

Eidenberger, R. . ...................301

Fernández, L. . . . . . . . . . . . . . . . . 423

Fiegert, M. ....................... 301

Fietz, A. ........................ 115

Figl, M. ....................... 206

Filipescu, A. ..................... 161

Fodor, G. . ...................... 180

Folgheraiter, M. .................. 72

Fritsch, D. ...................... 115

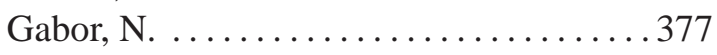

Galán, M. .......................246

Gams, A. ........................ 32

Garzón, M. ..................... 246

Gattringer, H. . . . . . . . . . . . . 192

Gentes, S. . ..................... 377

Gersdorf, B. .................... 174

Giamberardino, P. ................. 309

Gil, P. ........................ 153

Go, S. ...................... 409

Grimminger, F. . . . . . . . . . . . . . 72

Grundmann, T. ..................... 301

Guersi, N. ..................... 368

Hajdinjak, B. ....................212

Halme, A. ..................... 232

Hamdan, H. . . . . . . . . . . . . . . . . 295, 433

Han, Y. ....................... 89

Hawkes, D. ..................... 206

Herbulot, A. .................... 98

Herrero-Carrón, F. .................. 441

Hoeller, F. ....................... 186

Hoffmann, A. ................... 437

Hoffmann, J. ..................... 121

$\mathrm{Hu}, \mathrm{M} . \ldots \ldots \ldots \ldots \ldots \ldots \ldots \ldots . \ldots . \ldots . \ldots 206$

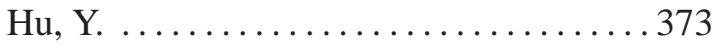

$\mathrm{Hu}, \mathrm{Z} . \ldots \ldots \ldots \ldots \ldots \ldots \ldots \ldots . \ldots . \ldots . \ldots . \ldots 232$ 


\section{AUTHOR INDEX (CONT.)}

Hui, S. . . . . . . . . . . . . . . . . . 174

Iglesias, R. . . . . . . . . . . . . . . . . 395

Jackisch, S. . . . . . . . . . . . . . 115

Jaffe, J. . . . . . . . . . . . . . . . . . . . . 89

James, D. . . . . . . . . . . . . . . . . . . . 335

Jang, J. . . . . . . . . . . . . . . . . . . . 340

Jara, C. . . . . . . . . . . . . . . . . . . 153

Ji, S. ................... . 403

Joly, C. . . . . . . . . . . . . . . . . . . . 281

Jordan, M. . . . . . . . . . . . . . . 72

Junez-Ferreira, C. . . . . . . . . . . . . . . . . 344

Kelley, R. ....................315

Khokar, K. .......................446

Kim, H. ...................... 340

Kim, S. . . . . . . . . . . . . . . . . . 340

King, C. ...................... 315

Kirchner, F. . ................. 72

Knoll, A. ...................... 289

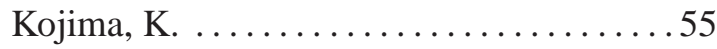

Kostić, D. ..................663

Kourd, Y. . . . . . . . . . . . . . . . 368

Koziorek, J. . . . . . . . . . . . . . . . 427

Kroemer, O. ...................447

Krüger, B. ................... 121

Lam, J. ..................... . 373

Langerwisch, M. . . . . . . . . . . . . 327

Langius, S. . . ................ 216

Laumond, J. ..................... 22

Lazea, G. . . . . . . . . . . . . . . . . 180

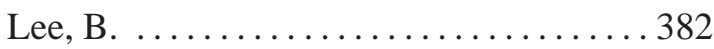

Lee, S. ..................... 403

Lee, Y. . . . . . . . . . . . . . . 354, 409

Lefebvre, D. . . . . . . . . . . . . . 364, 368

Lenain, R. . . . . . . . . . . . . . . . . . . 109

Liang, J. . . . . . . . . . . . . . . . . . . 373

Lichiardopol, S. . . . . . . . . . . . . . . 39

Liu, W. . . . . . . . . . . . . . . . . 222

Madani, K. ................... 360

Magid, E. ....................4415

Manea, I. .......................... 198

Manta, F. ........................... 198

Marín, J. . . . . . . . . . . . . . . . . . .4423

Mazur, A....................15

Montecillo-Puente, F. .............. 22

Morales, E. ....................... 79
Müller, T. ..................... 289

Muñoz-Meléndez, A. ............... . 79

Mutib, K. ................ 295, 433

Nebot, P. ......................... 399

Nicolescu, M. ................... 315

Nijmeijer, H. ........... 39, 55, 63

Nikolakopoulos, G. . . . . . . . . . . . . 260

Oguchi, T. .................. 55

Oztop, E. ..................... 212

Palacios-García, A. .............. 79

Park, M. ................. 382, 409

Pastor-Gomez, N. . . . . . . . . . . . . . . . . 344

Payá, L. ......................... 423

Penney, G. ....................... 206

Pereira, F. . . . . . . . . . . . . . 129, 135

Peters, J. . . ................. . 47

Petiteville, A. .................. 268

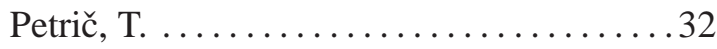

Petrişor, A. .................... 295

Piater, J. .................. 47

Pomares, J. . . ................. 153

Přeučil, L. .................... 141

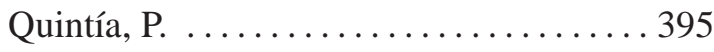

Ramík, D. .................... 360

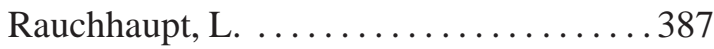

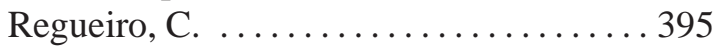

Reif, W. ................... 437

Reinoso, Ó. ..................... 423

Restrepo, D. .................. 167

Restrepo-Giraldo, J. . .............. 167

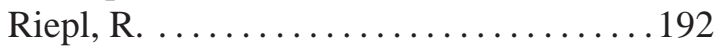

Rives, P. ................... 281

Rodríguez, F. . ................4441

Rodríguez, M. .................. 395

Röhling, T. ................... 186

Rossi, C. .................. 147, 246

Roszkowska, E. ................ 15

Roussos, N. .................... 260

Rueckert, D. .................. 206

Ruiz, O. ..................... 167

Sabourin, C. . . . . . . . . . . . . . . 360

Salles, E. ....................... 129

Saska, M. .................... 141

Schierl, A. ..................... 437

Schimschar, A. .................. 387 


\section{AUTHOR INDEX (CONT.)}

Schmidt, S. . ................... 72

Schneider, M. ...................... 301

Schulz, D. .....................5, 186

Serbencu, A. ................. 161, 240

Shah, M. ...................... 335

Shon, W. ..................... 403

Short, M. ...................... 222

Silson, P. ....................... 335

Solarski, T. .................... 427

Solea, R. ......................... 161

Sreenivasa, M. .................... 22

Stipa, T. ....................... 232

Suchodolski, T. ......................321

Sung, K. ............................ 382

Taima, Y. ...................... 222

Tavakkoli, A. ...................... 315

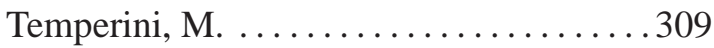

Thuilot, B. ....................... 109

Torres, F. . . . . . . . . . . . . . . . . 153

Tran, B. ........................ 289

Trilla, L. .......................... 348

Tsourdos, A. ....................... 335

Tsubouchi, T. ................... 415

Vacariu, L. ....................... 180

Vainio, M. ...................... 232

Vala, D. ....................... 427

Varona, P. .......................441

Vassallo, R. ................ 129, 135

Velasco-Avalos, F. ................. 344

Visel, B. ........................ 115

Vistein, M. ......................437

Vonásek, V. ...................... 141

Wagner, B. ......................... 327

Wolczowski, A. ................... 321

Wouw, N. .......................... 39

Ziv, N. ........................... 354

Žlajpah, L. ....................... 32

Zouari, B. ...................... 252 